Technische Hochschule Wildau

$+$

Brandenburgische Technische Universität

Cottbus-Senftenberg

$\rightarrow$

Innovation Hub 13

fast track to

T R A N S F E R

Working Paper No 001

2021

From InnoMix to

University-Industry Collaboration: Fostering Exchange at Eye Level

Carsten Hille, Daria Morcinczyk-Meier, Sarah Schneider and Dana Mietzner 
fast track to transfer, die Working Paper Series des Innovation Hub 13, ermöglicht es Projektmitarbeiter:innen und Kooperationspartner:innen sowie weiteren an der Thematik des Wissens- und Technologietransfers interessierten Wissenschaftler:innen und Praktiker:innen, ihre Forschungsergebnisse und praktischen Erfahrungen der wissenschaftlichen Community sowie einer breiten Öffentlichkeit zur Diskussion zu stellen. Als Instrument zum "fast track to transfer" bietet sie die Möglichkeit, Ergebnisse, Einblicke und Erkenntnisse schnell zu veröffentlichen. Darüber hinaus soll sie den Diskurs mit Akteur:innen aus Wissenschaft, Wirtschaft, Verwaltung, Kultur und Kunst sowie der Zivilgesellschaft fördern, der Information dienen und dazu einladen, sich in die Diskussion um die Zukunft des Wissens- und Technologietransfers einzubringen.

www.innohub13.de/workingpaperseries

Zitationsvorschlag:

Hille et al., 2021. From InnoMix to University Industry Interaction.

Fast track to transfer (working paper series), No. 001,

DOI: 10.15771/innohub_1

Das Dokument erscheint unter der Creative-Commons-Lizenz

Namensnennung 4.0 International (CC BY 4.0)

\section{fast track to \\ T R A N S F E R}

Working Paper Series

Technische Hochschule Wildau

Hochschulring 1

15745 Wildau

www.th-wildau.de

Brandenburgische Technische Universität Cottbus-Senftenberg

Platz der Deutschen Einheit 1

03046 Cottbus

www.b-tu.de

Weitere Informationen zum Innovation Hub 13 und zu Transfer Transfer finden Sie unter www.innohub13.de

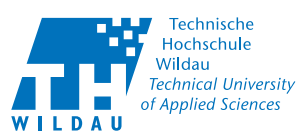

Brandenburgische Technische Universität Cottbus - Senftenberg
Der "Innovation Hub 13 - fast track to transfer“ der Technischen Hochschule Wildau und der Brandenburgischen Technischen Universität Cottbus-Senftenberg gehört zu den 29 ausgewählten Gewinnern der Bund-LänderFörderinitiative „Innovative Hochschule”, ausgestattet mit Mitteln des Bundesministeriums für Bildung und Forschung BMBF und des Landes Brandenburg. Weitere Informationen finden Sie unter www.innovative-hochschule.de 


\title{
From InnoMix to University-Industry Collaboration: Fostering Exchange at Eye Level
}

Hille, Carsten, Technical University of Applied Sciences Wildau, "Innovation Hub 13 - fast track to transfer"

Morcinczyk-Meier, Daria, Technical University of Applied Sciences Wildau, "Innovation Hub 13 - fast track to transfer"

Schneider, Sarah, Technical University of Applied Sciences Wildau, "Innovation Hub 13 - fast track to transfer", sarah.schneider@th-wildau.de Mietzner, Dana, Technical University of Applied Sciences Wildau, "Innovation Hub 13 - fast track to transfer"

\begin{abstract}
In this paper, we address a specific tool-InnoMix - that is implemented to overcome the lack of university-industry interaction in a selected region facing structural change with its corresponding impact on the economy and society. InnoMix is facilitated and implemented by university-based transfer scouts who act as mediators and translators between the players of the regional innovation system. These transfer scouts are part of the Innovation Hub 13, in which the region's partners and stakeholders, infrastructures and competencies are systematically networked with each other to set new impulses for knowledge and technology transfer. These new impulses are brought into the region through new transfer approaches ranging from people and tools to infrastructure. InnoMix can be considered to be a highly interactive tool to overcome the weak, direct interaction between researchers and potential corporate partners in the region to foster strong collaboration between academia and industry. InnoMix especially aims to strengthen interdisciplinary exchange to shed light on cross-disciplinary perspectives. For that reason, transfer scouts focusing on transfer activities related to the life sciences, digitalisation and lightweight construction are involved in the implementation of InnoMix. Based on 11 InnoMix running since 2019, we provide insights into the planning and preparation phase of InnoMix and the selection of relevant topics and requirements for matching participants. Furthermore, we clearly indicate which formats of InnoMix work best and in which way university-industry interactions could be curated after InnoMix is implemented.
\end{abstract}

\section{Keywords}

collaboration, transfer scouts, knowledge and technology transfer (KTT), innovation, innovation hub, networking/matchmaking 


\section{$1 \quad$ Introduction}

Many regions face major economic and social challenges, especially structurally weak regions and areas affected by the loss of dominant production sectors. One region, characterised by considerable structural change, mainly caused by the phasing out of coal, is the Lusatia region in the south-east part of Germany. Lusatia transcends the boundaries of the federal states of Brandenburg and Saxony, comprises ten districts and two independent cities in southern Brandenburg and northern Saxony and has a total population of 2.1 million (Gemeinsame Wissens- und Technologietransferstrategie TH Wildau und BTU Cottbus-Senftenberg, 2017). Furthermore, this region is characterised by a highly heterogeneous economic structure. The business landscape can be described as having a few large companies and numerous small and medium-sized enterprises (SMEs) having often settled around them. A significant proportion of SMEs are micro companies with fewer than 10 employees. According to the Berlin-Brandenburg Statistics Office, they account for around $90 \%$ of all companies in Brandenburg (Amt für Statistik Berlin-Brandenburg, 2020).

Key economic and social issues in this region are (1) the energy transition and the associated disappearance of the former coal industry and its effects on the economy and society, (2) the consequences of demographic change, (3) shifting work and life conditions due to digitalisation and (4) local policies and activities of companies and individuals that meet sustainability goals related to climate change.

To support the ongoing structural change, a wide range of policy interventions, programmes, projects, networks and initiatives have been established. Beside existing, new and restructuring companies, government agencies and civil society, universities play a key role in innovation and progress in a region facing structural change (see e.g., Trippl et al., 2015; Maier \& Trippl, 2011 describe the case of Software Park Hagenberg in the province of Upper Austria).

There is wide range of relevant literature discussing the role of universities in regional development (Hessels \& van Lente, 2008; Gibbons et al., 1994; Nowotny et al. 2001). The concepts discussed in the literature emphasise the role of universities engaged in collaborative research with other organisations to produce knowledge that is relevant to their environment. Here, universities are discussed as contributing to solve societal problems (Nowotny et al., 2001).

Beside the training and education of young people for a highly complex and dynamic working environment, knowledge and technology transfer (KTT) from academia to industry may have the potential to underpin structural change (see also the discussion on the importance of universities for regional development in e.g., Asheim et al., 2011; Tödtling \& Trippl, 2005; Organisation for Economic Co-operation and Development, 2007; Kempton, 2015).

With the initiative Innovation Hub 13, two universities in the selected region, Technical University of Applied Sciences Wildau (TUAS Wildau) and Brandenburg Technical 
University Cottbus-Senftenberg (BTU Cottbus-Senftenberg), have started to develop, adapt and establish new approaches and tools to accelerate KTT processes in the regional innovation system (see https://innohub13.de/). The Innovation Hub 13 allows the region's partners or stakeholders, infrastructures and competencies to be systematically networked with each other to set new impulses in KTT. Here, transfer activities are based on results and findings from research and development. Transfer is understood as a multidirectional, discursive and interactive process between the universities and their environments. Thus, players from industry, academia, politics and administration as well as civil society interact according to the quadruple helix approach (see e.g., Cavallini, Soldi, Friedel \& Volpe 2016). The goal is mutual development through an ongoing exchange of knowledge, technology and learning processes (see e.g., Gemeinsame Wissens- und Technologietransferstrategie der TH Wildau und BTU Cottbus-Senftenberg, 2017).

New impulses are brought into the region through highly transfer approaches ranging from people and tools to infrastructure. Transfer scouts (people) act as mediators and translators between the players of the regional innovation system (Schneider \& Mietzner, 2020). Test beds (infrastructure) are being implemented to make innovative technologies perceptible for everyone. Showrooms (infrastructure) are being set up as "shop windows" to civil society and companies making newly developed technologies and processes tangible. Universities' subsidiaries in the region (infrastructure) act as a contact point for civil society and companies. Furthermore, digital tools like virtual tours (tools) in university labs and technology radars (tools) make technological development within academia comprehensively visible and perceptible (see https://innohub13.de for further examples related to people, tools and infrastructure).

Nevertheless, there can still be a lack of direct interaction between academia and industry on the level of joint developments. The reasons are manifold, like a lack of resources, time and awareness, and that also includes the lack of knowledge about each other's competencies and needs as well as possibilities of collaboration. One highly interactive tool that overcomes the lack of direct interaction between researchers and potential corporate partners in the region-InnoMix - is implemented by the transfer scouts to foster collaboration between academia and industry.

The aim of this paper is to deepen the understanding about the InnoMix approach as a tool to foster collaboration between academia and industry at "eye level". We will deliver further insights on the preparation, implementation and follow-up of InnoMix and will discuss the main outcomes and transfer paths of the corresponding InnoMix, which has been implemented since 2019 . 


\section{InnoMix: A Networking Approach}

Transfer scouting is a key approach in Innovation Hub 13 and is eminently suitable for mediating between academia and industry and, in the case of the Innovation Hub 13, especially between academia and regional companies (Schneider \& Mietzner, 2020; see also the literature review on transfer intermediaries in Noack \& Jacobsen, 2021). Noack and Jacobsen (2021) emphasise in their research the extension of the intermediating functions to co-constructive knowledge production, when transfer scouts include their own ideas and expertise in transfer projects and therewith actively participate in the coconstruction of new technological knowledge. Transfer scouts undertake activities in their explicit intention to contribute to regional development (Noack \& Jacobsen, 2021).

In the Innovation Hub 13 region, a regular exchange of ideas, mediation between academia and regional companies and the bundling of existing competencies and infrastructures of the region is necessary to contribute to regional development. In InnoMix, which can be described as a form of networking, transfer scouts bring stakeholders around the table on a specific topic and sensitise them towards joint transfer activities. InnoMix especially aims to strengthen interdisciplinary exchange to shed light on cross-disciplinary perspectives and ultimately collaboration on new ideas and possible solutions. In doing so, it is important that the experts in their respective fields mutually exchange ideas. Transfer scouts translate between different players and identify potential areas cooperation. A key advantage as well as challenge is InnoMix's highly interdisciplinary approach, which goes beyond well-established forms of networking. To foster cross-disciplinary perspectives, transfer scouts working in the field of life sciences, digitisation and lightweight construction are involved. The highly interdisciplinary approach is underlined with the term "InnoMix"-innovation based on research and development from different disciplines as well as a mix of experts (e.g., researchers, implementers, business developers and civil society members).

Nevertheless, the basic idea was inspired from other forms of networking that are characterised by (1) the selection of a very specific topic, challenge or issue of interest and (2) a relatively small numbers of participants (e.g., 10 scientists and 10 corporates) with different perspectives on the topic. In general, the InnoMix can be defined as a highly structured and goal-oriented format, which includes the discussion of a specific interdisciplinary topic by experts from different fields as a starting point for collaboration.

Table 1 indicates the details of the considered InnoMix events. These details are fundamental for the identification of insights and implications about the InnoMix approach as a tool to foster collaboration between academia and industry as equal partners. 


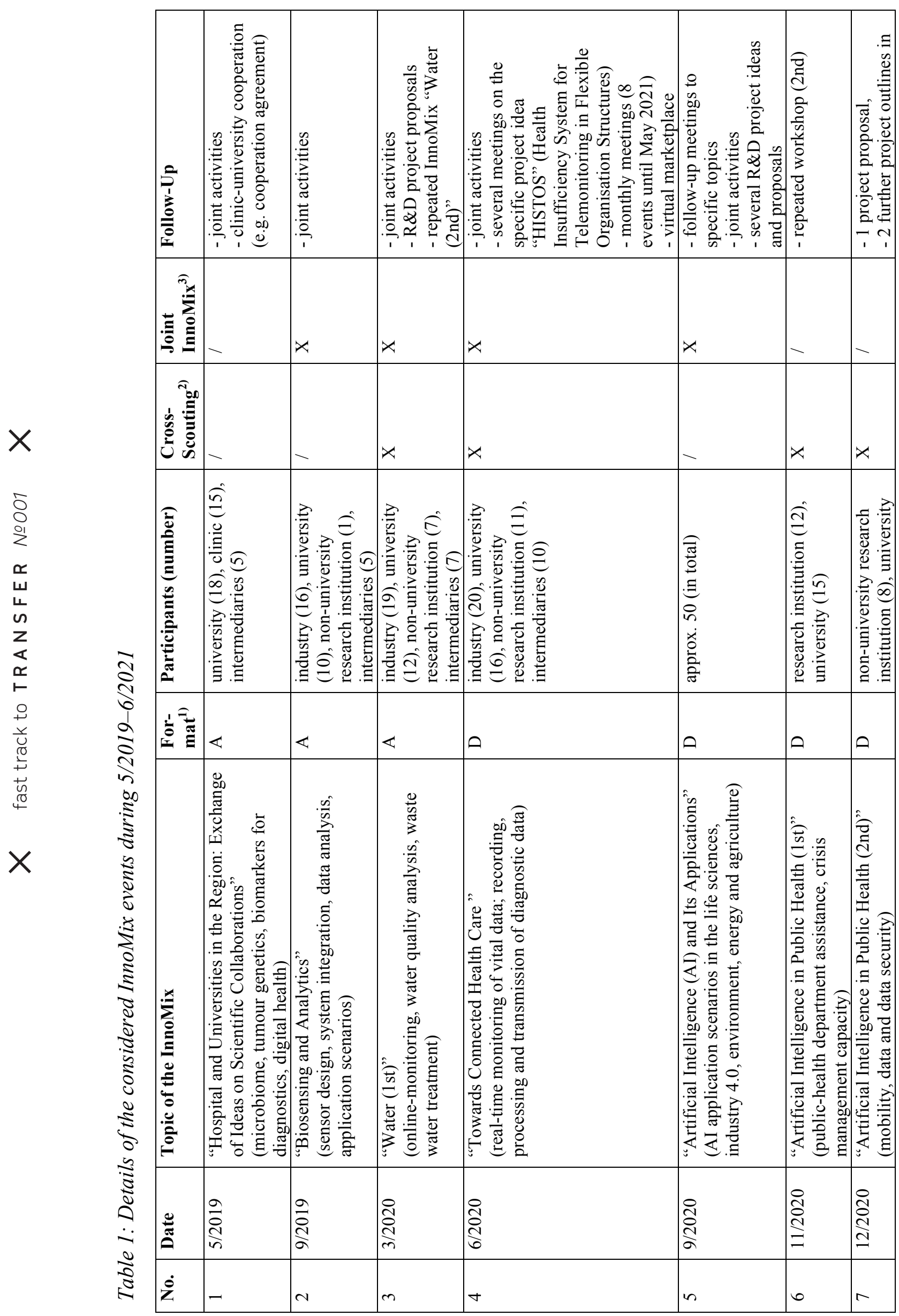




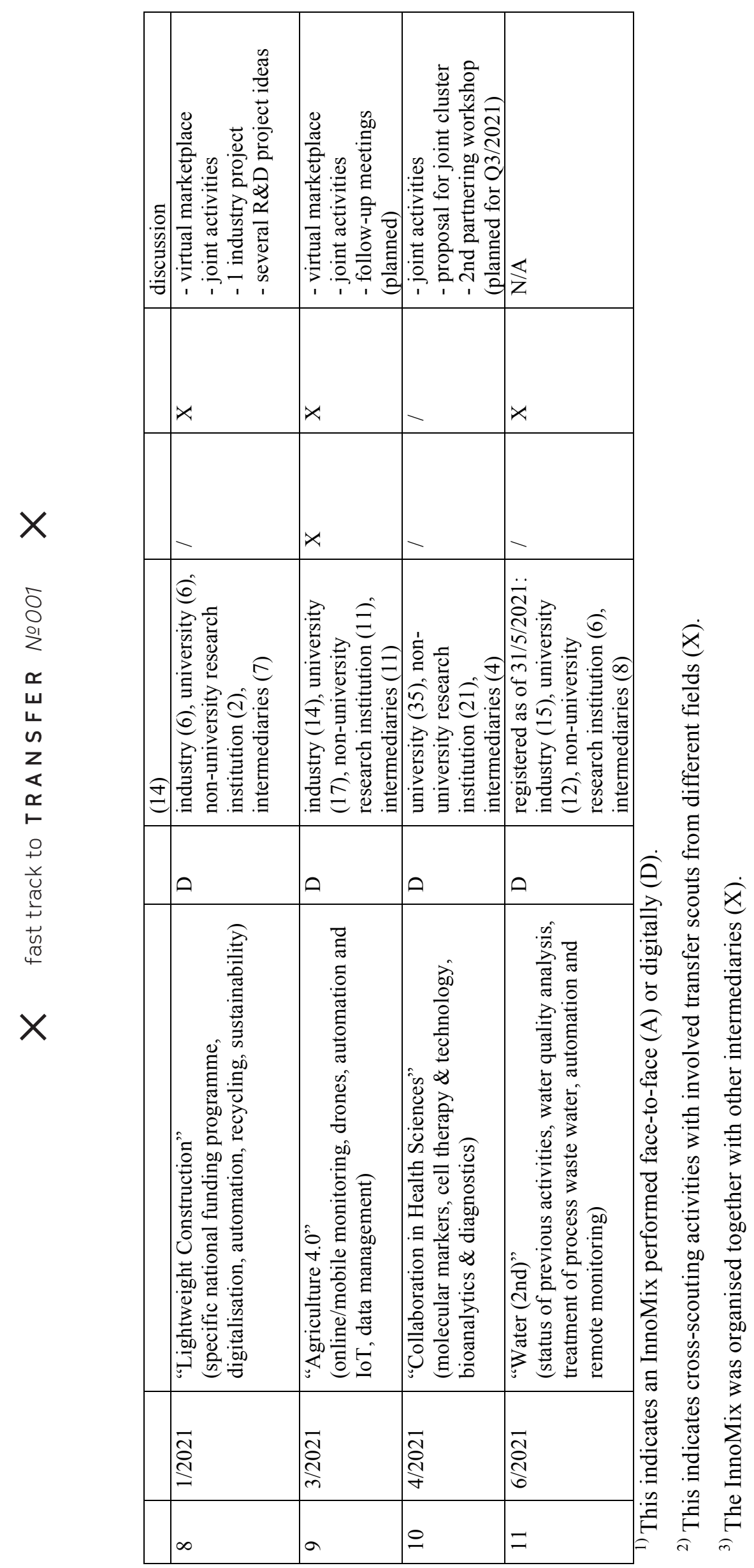

From InnoMix to University-Industry Collaboration: Fostering Exchange at Eye Level Carsten Hille, Daria Morcinczyk-Meier, Sarah Schneider and Dana Mietzner | 2021 


\section{Results and Discussion}

Eleven InnoMix events have been conducted by the transfer scouts since May 2019; five of them could be considered explicitly on interdisciplinary topics (cross-scouting) (see Table 1). With this experience, the key steps for planning, implementing and following up an InnoMix could be standardised and are outlined in general.

\subsection{Time for planning and preparation}

An early start on preparation is essential for a successful event. If new formats and content are to be implemented, a planning phase of 3-4 months in advance is necessary. If the InnoMix is based on established structures or routines, 2 months for the planning phase are sufficient. A crucial factor is mainly the availability of potential participants for the InnoMix.

\subsection{Identification of relevant topics}

The topics discussed in the InnoMix arise from different occasions. Through discussions of the transfer scouts with researchers at both universities, topics that had already been worked on in one way or another by some researchers emerged, but interdisciplinary, cross-group collaboration did not yet exist. Here, for example, the transfer workshop "Hospital and Universities in the Region: Exchange of Ideas on Scientific Collaborations" in May 2019 was a starting point to get to know existing competencies in the biomedical field and to identify research activities with a local hospital. Another occasion for an InnoMix could be a current funding announcement. For example, at the InnoMix event "Lightweight Construction" in January 2021, participants were prepared to submit proposals to the Lightweight Construction Technology Transfer Program of the German Federal Ministry for Economic Affairs and Energy. Topics that play an important role in local industry could also be the reason for conducting an InnoMix. For example, for the InnoMix "Water (1st)" in March 2020, numerous relevant companies and research institutions that were active in the fields of water cycles, water quality and remote monitoring were identified in advance. The linking of different disciplines in so-called cross-scouting activities were also an occasion for networking events. For example, at the InnoMix "Towards Connected Health Care" in June 2020, expertise from the biomedical field was successfully linked with the field of digitalisation. 


\subsection{Identification and matching of participants}

After defining the topic of an InnoMix, it is important for the transfer scouts to find suitable partners. On the one hand, this made it possible to expand the available network for advertising and approaching potential participants. On the other hand, parallel structures could be avoided and resources could be bundled. Ultimately, several organisations in the Lusatia region are working with the goal of improving the networking of stakeholders. The transfer scouts of Innovation Hub 13 are well connected within the universities, and they can identify scientific experts who could serve as potential collaborators. To identify suitable companies, the transfer scouts relied primarily on the industry-specific clusters of the Economic Development Agency Brandenburg. Thus, transfer scouts in six of the eleven InnoMix events have been organised in cooperation with individual or several industry-specific cluster managers (Economic Development Agency Brandenburg) so far. The inclusion of existing local competence networks with direct access to topically relevant companies and research institutions also appears promising. In the cases of specific funding announcements as occasion to conduct an InnoMix, the project management agency was involved to offer the participants detailed knowledge and further background information, e.g., in InnoMix "Lightweight Construction".

After narrowing down the topics and finding cooperating partners, a list of important participants was formed. A preliminary inquiry with participants who were essential for the InnoMix proved to be useful in determining the final date for the respective InnoMix. When selecting the date, it also seemed sensible to avoid weekly marginal dates (Mondays and Fridays) and to schedule the event in the afternoon or at the end of a working day. Depending on the group of participants, university activities (e.g., lecture times), industry-specific exhibitions and congresses and similarly themed events in the region should also be taken into account in advance. Depending on the chosen format, a duration of 2-4 hours was planned for a networking event.

One difference between the InnoMix and other networking events is the target groupspecific pre-selection of participants by the transfer scouts and partners (prematching), instead of broad, open and non-specific advertising of the event. The expected benefit for participants should be a precise matching of the players (guaranteed quality and accuracy of fit). In this way, content-related topics and contributions can be better coordinated, and the presence of specific target groups (e.g., academia, industry, intermediaries) can be better balanced. In addition, active participation of most participants in the event is ensured, and the proportion of passive listeners is kept low. Addressing participants directly also creates the feeling that they are valued and that their topics are really noticed. Prematching is indeed very time-consuming, but the positive experiences and feedback at previous InnoMix events justified the effort. To ensure that all participants can actually have their say and can be heard, the number of participants in the InnoMix event was limited to approximately 50 people. This size also allows optimal support to the participants by the organisers. 


\subsection{Determination of InnoMix formats}

The next step is to determine the suitable format. Originally, InnoMix events are planned exclusively face-to-face. The idea is to select an appropriate location at one of the university campuses. In addition to networking in an informal atmosphere, this would also allow for thematically relevant campus and lab tours. The InnoMix works face-to-face as well as in a digital environment, although not all elements can be replicated 1:1 in the digital format. In particular, small talk during the obligatory coffee breaks is difficult to reproduce digitally. Nevertheless, the use of collaborative tools, energizers, live surveys or prepared videos adds value to a digital InnoMix. However, the time and cost involved in face-to-face events should not be underestimated. In the future, it is therefore conceivable to plan a hybrid InnoMix. Digital introductory InnoMix events to get to know potential partners and topics are then feasible, followed by face-to-face events to discuss specific topics on a smaller scale.

For a face-to-face InnoMix event, a short introduction round of all participants is useful. This was arranged, for example, at the InnoMix "Biosensing and Analytics" by asking all participants to report only three keywords about themselves to the following questions: Who am I? What can I do? What do I need? A different approach was conducted at the transfer workshop called "Hospital and Universities in the Region: Exchange of Ideas on Scientific Collaborations". Here, all participants briefly introduced themselves in a 3-minute pitch with the help of two PowerPoint slides. Afterwards, there were 2 minutes for short questions from the audience. At a digital InnoMix, however, this kind of plenary introduction did not work. Here, participants had to individually prepare before the event with the transfer scouts helping them to compile a specific participant profile. After the round of introductions, participants gathered at digital discussion tables on predefined topics or topics that had arisen on the spot. Prior allocation of the participants to the tables helped to initiate the discussions. Nevertheless, participants could always change tables. The discussion at the tables was facilitated by the transfer scouts. With the help of whiteboards, key points of the discussion were immediately recorded and were also made available for participants who joined later. A different structure was used for a digital InnoMix. For example, at the InnoMix "Agriculture 4.0", contributions were initially made in the form of short 10-minute presentations to raise awareness on certain topics. Then, more in-depth discussions on these and other topics took place in sub-rooms during several breakout sessions. With the help of digital tools (e.g., Miro, Mentimeter), the results could be saved and made available afterwards.

With digital InnoMix events, a virtual marketplace was introduced. This was accompanied by the fact that the topics of an InnoMix could not be fully explored within a single event. Rather, the InnoMix was merely the kick-off to subsequent meetings. Given the continuous documentation of the results and sustainable development, e.g., of an initially loose network out of the InnoMix, a virtual marketplace was possible. The deposited data were generally divided into five columns 
on the digital pinboard: news and dates, project ideas and cooperation offers, potential partners with deposited profiles and contact details, funding opportunities and the contact person at Innovation Hub 13 (see Figure 1). An essential requirement for the virtual marketplace was that each participant or interested person (depending on the distribution of the marketplace) could deposit his or her own new entries. In the end, however, the service provided by the Innovation Hub 13 transfer scouts to keep the marketplace up to date was particularly well received. Several free and paid digital solutions are available for the implementation of such a virtual marketplace (e.g., Conceptboard, Miro, Mural, Padlet, Wekan); the transfer scouts decided to use the General Data Protection Regulation (GDPR) compliant, open-source Kanban tool Wekan after some tests (see Figure 1). For better visibility and clarity for new participants in this round and for initiating new activities, this virtual marketplace has been used. Indeed, the virtual marketplace of the InnoMix "Towards Connected Health Care" was able to attract further relevant players, who had not been in the focus of the transfer scouts before. In some InnoMix events, the virtual marketplace facilitated further networking, according to what participants told the transfer scouts.

Figure 1: Example of a Virtual Marketplace for Continuous Documentation of Activities of an InnoMix Using Wekan

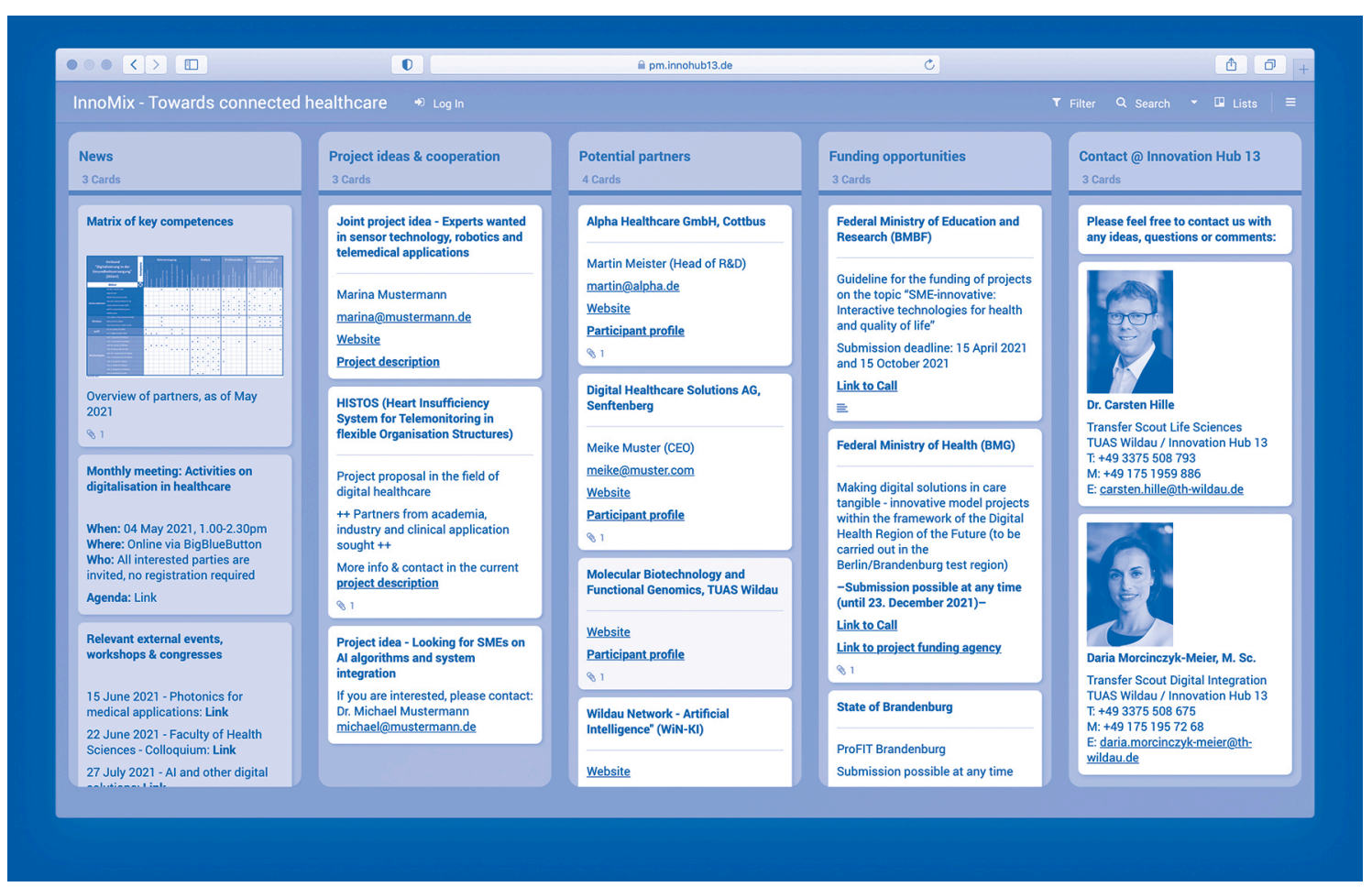

Note. Contents shown are partly fictitious. 


\subsection{Preparation of InnoMix material}

To support the direct approach of potential participants, a flyer is helpful to announce the InnoMix. Here, the main topic and possible discussion points could be introduced briefly and concisely on one page. Email, telephone and personal conversations are equally useful as channels of communication. The event information could also be stored on a separate home page. The primary advantage of an event home page for an InnoMix is obtaining centralised, GDPR-compliant details of participants (name, organisation and email address). In addition to including a data protection declaration, it is also useful to indicate that contact data would be passed on to all participants and that pictures would be recorded and used. Because of targeted invitation of participants, the event home page was not publicly advertised.

To effectively prepare all participants for the InnoMix, a short profile of them should be developed in advance. The essential information should be brief and compiled on one page (see Figure 2). This includes the available core competencies and infrastructures, previous $R \& D$ projects as reference, the sought partnership/cooperation and contact details. These profiles could be summarised in a compendium and sent to the participants about one week before the InnoMix. For face-to-face events, the compendium is also provided as a printout on the day of the event. Providing a blank field on each profile for notes is then particularly helpful.

Figure 2: Example of a Participant Profile.

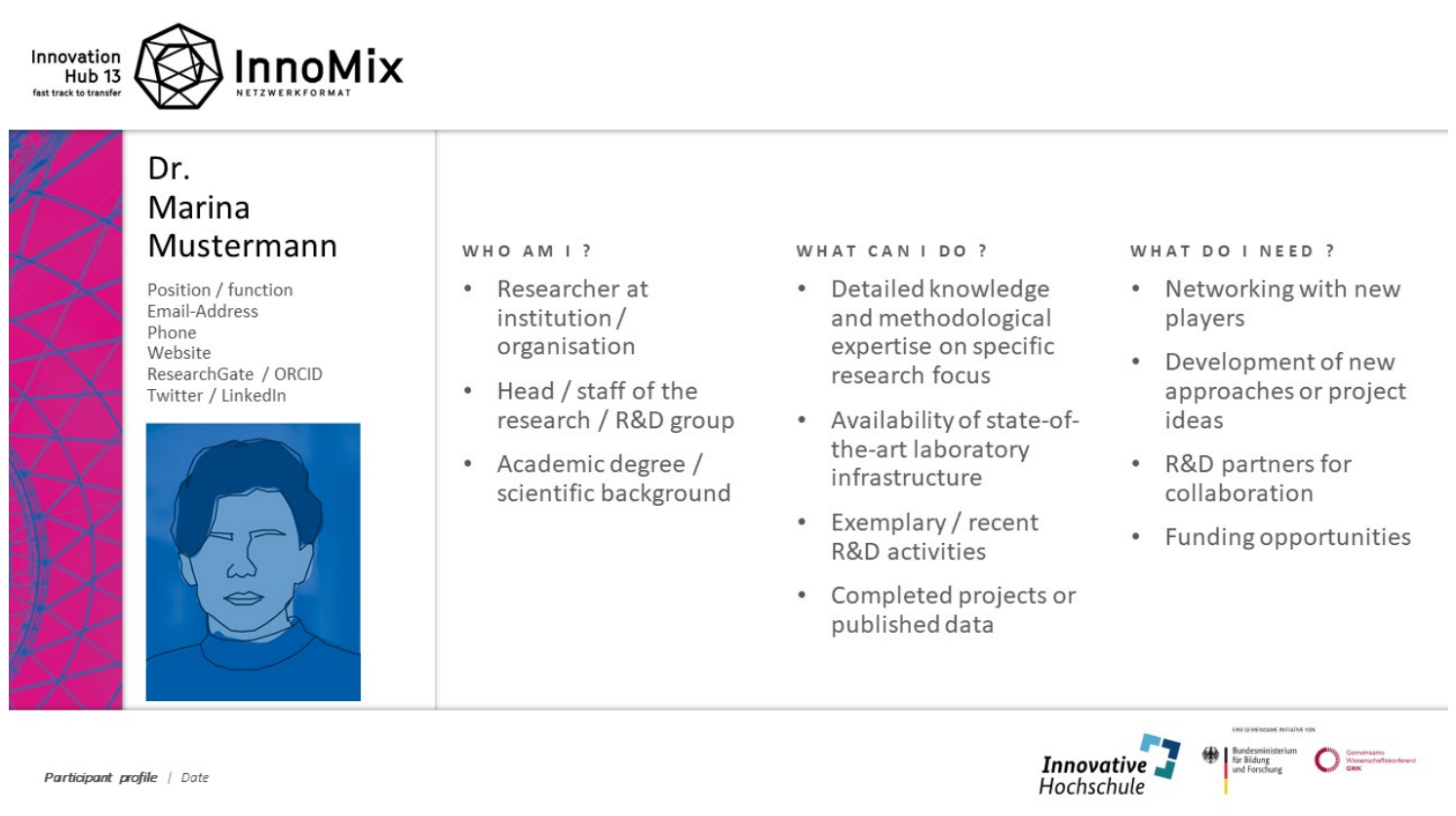




\subsection{Follow-up activities}

An InnoMix is only the kick-off to a variety of follow-up activities. Depending on the focus of the topic, the intensity of the follow-ups varies. At the InnoMix "Water (1st)" in March 2020, the focus was on a current funding announcement of the German Federal Ministry of Education and Research, among other things. Through the InnoMix, the transfer scouts were able to bring together relevant, previously unknown partners and promote a possible consortium. The transfer scouts subsequently provided support in sharpening the topic and submitting a proposal for a joint project. The InnoMix "Artificial Intelligence and Its Applications" in September 2020 initially had a broad theme. This InnoMix provided a general foray into the topic of artificial intelligence and opened up new perspectives. The more defined application scenarios were then explored in greater depth in several digital follow-up events. These follow-up events, moderated by the transfer scouts, took place in smaller groups of participants and allowed for intensive discussion of project ideas. The InnoMix "Towards Connected Health Care" in June 2020 took up an enormously relevant social topic. The first solid project ideas were already visible in the preparation for the InnoMix and were preselected for timely digital follow-up events. Two findings are interesting to observe here: on the one hand, there was a solid core of interested people, who regularly participated in the follow-up events. On the other hand, new, interested people with complementary skills and resources also became aware of the follow-up meetings. This resulted in a network of experts with shared interests, who met each month (they have already been meeting for 1 year), which led to the formation of an innovation lab. The intention of the monthly, digital exchange was to share new project ideas, potential partners and alternative application scenarios with all participants. Participants viewed the support provided by the transfer scouts in the technical organisation, agenda preparation and follow-up activities of the meetings as extremely valuable. The virtual marketplace has established itself as a useful platform for data storage. In this way, new funding opportunities could be explored, and a clear competence matrix of interested partners could be created. This helped in the evaluation of existing and required competences along the value chain of a chosen project idea. In the next step, it would be desirable if the network would develop into a firmly established (possibly also funded) network.

Despite the obvious utilisation paths after an InnoMix, it remains difficult to follow up on the concrete successes in terms of contact mediation, project ideas and proposals through to projects. This requires the transfer scouts to make consistent enquiries of the participants, as successes can occur in different time periods. In addition, not all activities can be traced back to a specific InnoMix. With the InnoMix "Water (2nd)" in June 2021, for example, the transfer scouts are trying to build on the findings of the InnoMix "Water (1st)" in March 2020. They shed light on activities already initiated and derived further activities. Indeed, one of their findings is that sustainable activities do not just emerge after a single event. Rather, many downstream steps are needed after the relevant players have been initially brought together. 


\section{Conclusion and Recommendations}

InnoMix is a promising nucleus to initiate diverse KTT activities. Participants highly value the intensive support provided by transfer scouts as it builds trust and motivates them. However, this requires well-prepared facilitation of the InnoMix with clear responsibilities assigned to the hosts. In this sense, on the one hand, transfer scouts play a key role in the preparation and implementation of InnoMix events. On the other hand, an InnoMix contributes significantly to the credibility of transfer scouts in their specific role.

The targeted selection of participants (prematching) and preparation with clearly structured participant profiles led to a rapid exchange of ideas. Participants found this approach effective in terms of "guaranteed quality" and "accuracy of fit". The intensive support provided by transfer scouts gave participants the feeling of "I am being taken care of" or "I am being understood and taken seriously". In this way, discussions between the potential transfer partners could be held as a dialogue of equal partnership.

The synergies of including other regional intermediaries as partners is evident-it pooled resources, increased visibility and significance of the InnoMix and enabled interested persons to participate in one joint event.

The InnoMix described in this paper was a starting point for different transfer paths. In general, there can be the following four generic paths: (1) a follow-up discussion in smaller groups, (2) new networks, (3) project proposals and (4) cooperation and $R \& D$ projects. For five out of eleven InnoMix events, concrete follow-up meetings on specific topics were conducted in smaller groups (partly with the help of the transfer scouts). In addition, there are ongoing activities in which players meet regularly, establishing a preliminary stage of permanent network structures. InnoMix led to project proposals, multilateral cooperation and $R \& D$ projects, which are intended to support the structural change in the Lusatia region. Overall, the findings so far show that InnoMix can be used to effectively bring together relevant players from academia and industry, so that the available competences, resources and existing challenges are known to all participants. This is a good basis for their further joint activities. However, the emerging activities and development steps from the InnoMix are often not clearly traceable for the transfer scouts. Here, the challenges the transfer scouts face include the necessary permanent asking of the players, the continuous recording of activities in a digital data management system and the clear mapping of the origins and effects of transfer activities.

So far, transfer scouts specifically addressed academia and industry. In the future, InnoMix will be opened up to other players of the quadruple helix. Beside academia and industry, the involvement of customers and users as representatives of the civil society (e.g., with regard to tests of acceptance of product features or overall solutions and usability tests) as well as policymakers and administrators (e.g., with regard to legal questions and regional prerequisites) could be promising for the further development of 
innovation in the selected region. Pilot rounds of InnoMix in which future users participated to report on their needs have been promising. For example, in the follow-up meetings of the InnoMix "Towards Connected Health Care" focussing on the HISTOS project idea, medical practitioners were invited because they would be the future users of the proposed medical device. Their insights and first-hand experience contributed significantly to the further development of the idea and gave the opportunity to modify the project objectives accordingly to the user's needs.

Furthermore, the linking of digital and face-to-face InnoMix events can help optimise the resource deployment of the transfer scouts and the participants. Currently, the transfer scouts are working on hybrid InnoMix formats, which can be initiated digitally (this is relatively easy to organise, with minimal effort from the participants). The start of the InnoMix in a digital format could allow for the exploration of relevant issues and corresponding players. After that, the face-to-face part of InnoMix could be used for a deep dive into the selected issue. Future InnoMix events will retain an interdisciplinary approach. We are convinced that incorporating different perspectives into the innovation process is a key aspect to better managing and solving future challenges in the Lusatia region.

\section{$5 \quad$ Funding}

The study is part of the transfer project "Innovation Hub 13 - fast track to transfer" (01/2018-12/2022), funded by the German Federal Ministry of Education and Research and the State of Brandenburg, which aims to develop, adapt and establish innovative tools to accelerate transfer processes. 


\section{References}

Book/Report Produced by an Organisation

Amt für Statistik Berlin-Brandenburg. Rechtliche Einheiten nach Bezirken bzw. Kreisen und Beschäftigungsgrößenklassen, (2018). https://www.statistik-berlin-brandenburg.de/

Cavallini, S., Soldi, R., Friedl, J., \& Volpe, M. (2016). Using the quadruple helix approach to accelerate the transfer of research and innovation results to regional growth, European Union Committee of the Regions. https://doi.org/10.2863/408040.

OECD. (2007). Higher education and regions: Globally competitive, locally engaged. Paris: OECD Publishing.

Journal Article

Asheim, B., Moodysson, J., \& Tödtling, F. (2011). Constructing regional advantage: Towards state-of-the-art regional innovation system policies in Europe? European Planning Studies, 19, 1133-1139.

Hessels, L., \& van Lente H. (2008). Re-thinking new knowledge production: A literature review and a research agenda. Research Policy, 37, 740-760.

Kempton, L. (2015). Delivering smart specialization in peripheral regions: The role of Universities, Regional Studies, Regional Science, 2(1), 488-495, https://doi.org/10.1080/21681376.2015.1085329.

Noack, A., \& Jacobsen, H. (2021). Transfer scouts: From intermediation to coconstructors of new knowledge and technologies in Germany. Research Policy, 50, 104-209.

Tödtling, F., \& Trippl, M. (2005). One size fits all?: Towards a differentiated regional innovation policy approach. Research Policy, 34, 1203-1219.

Trippl, M., Sinozic, T., \& Smith, H. L. (2015). The role of universities in regional development: Conceptual models and policy institutions in the UK, Sweden and Austria, European Planning Studies, 23(9), 1722-1740, https://doi.org/10.1080/09654313.2015.1052782

Website or Online Source

Gemeinsame Wissens- und Technologietransferstrategie der TH Wildau und BTU Cottbus-Senftenberg (2017). https://www.th-wildau.de/files/Forschungsservice/201702-17_Gemeinsame-Transferstrategie-BTU-THW_v14_final.pdf

Book

Gibbons, M., Limoges, C., Nowotny, H., Schwartzman, S., Scott, P., \& Trow, M. (1994). The new production of knowledge: The dynamics of science and research in contemporary societies. SAGE.

Nowotny, H., Scott, P., \& Gibbons, M. (2001). Re-thinking science: Knowledge and the public in an age of uncertainty. Polity Press. 
Paper in Conference Proceedings

Maier, G., \& Trippl, M. (2011). New path creation in old industrial regions: The case of the Software Park Hagenberg in the Province of Upper Austria. 51st European Congress of the RSAI. Barcelona, Spain.

Schneider, S., \& Mietzner, D. (2020). Role and impact of transfer scouts in universityindustry interaction. Submitted and accepted for poster presentation in Next Practice \& Poster Book Challenges and Solutions for Fostering Entrepreneurial Universities and Collaborative Innovation, University-Industry Innovation Network, UniversityIndustry Interaction Conference, 9-11 June 2020. 